\title{
Pre- and during-labour predictors of low birth satisfaction among Iranian women: a prospective analytical study
}

\author{
Jila Nahaee ${ }^{1}$, Sakineh Mohammad-Alizadeh-Charandabi² ${ }^{*}$, Fatemeh Abbas-Alizadeh ${ }^{3}$, Colin R. Martin ${ }^{4}$,
} Caroline J. Hollins Martin ${ }^{5}$, Mojgan Mirghafourvand ${ }^{6}$ and Hadi Hassankhani ${ }^{7}$

\begin{abstract}
Background: Maternal childbirth dissatisfaction has short- and long-term negative effects on the mothers' health and life, as well as on relation with her child and family. Due to lack of studies in Iran and other counties, we aimed to determine pre- and during- labour predictors of low birth satisfaction.

Methods: Seven hundred women with low risk singleton pregnancy participated in this prospective analytical study. The participants were hospitalized for vaginal delivery with fetus in cephalic presentation and gestational age of $37^{0}-41^{6}$ at two teaching centers in Tabriz (Iran). Woman characteristics, anxiety state (using Spielberger inventory) and dehydration were assessed at cervical dilatation of $4-6 \mathrm{~cm}$. Iranian (Persian) birth satisfaction scalerevised was applied 12-24 h after birth. Multiple linear regression was used to determine the predictors.

Results: Excluding 26 women who were outliers, 674 women were analyzed. The mean birth satisfaction score was 23.8 (SD 6.5) from an attainable score of 0-40. The during-labour predictors of low birth satisfaction score were severe and moderate anxiety, labour dystocia, insufficient support by staff, vaginal birth with episiotomy and tear, emergency cesarean section, labour induction and labour augmentation with oxytocin, and woman dehydration. The pre-labour predictors included being primiparous, sexual and emotional violence during pregnancy, gestational age of $40^{\circ}-41^{6}$, preference for cesarean section, no attendance at pregnancy classes, and insufficient household income. The proportion of the variance explained by the during-labour variables was $75 \%$, by pre-labour variables was $14 \%$ and by overall was $76 \%$.

Conclusions: The controllable during-labour predictors explains most of the variance of the satisfaction score. It seems that responding to women's physical and psychological needs during labour and applying less interventions could improve women's childbirth satisfaction.
\end{abstract}

Keywords: Satisfaction, Risk factors, Predictors, Childbirth, Labour, Iran, Ethical code: IR.TBZMED.REC.1397.624.

\footnotetext{
*Correspondence: alizades@tbzmed.ac.ir; mhammadalizadehs@gmail.com

${ }^{2}$ Social Determinants of Health Research Center, Department of Midwifery,

Faculty of Nursing and Midwifery, Tabriz University of Medical Sciences,

Tabriz, Iran

Full list of author information is available at the end of the article
}

(c) The Author(s). 2020 Open Access This article is licensed under a Creative Commons Attribution 4.0 International License, which permits use, sharing, adaptation, distribution and reproduction in any medium or format, as long as you give appropriate credit to the original author(s) and the source, provide a link to the Creative Commons licence, and indicate if changes were made. The images or other third party material in this article are included in the article's Creative Commons. licence, unless indicated otherwise in a credit line to the material. If material is not included in the article's Creative Commons licence and your intended use is not permitted by statutory regulation or exceeds the permitted use, you will need to obtain permission directly from the copyright holder. To view a copy of this licence, visit http://creativecommons.org/licenses/by/4.0/ The Creative Commons Public Domain Dedication waiver (http://creativecommons.org/publicdomain/zero/1.0/) applies to the data made available in this article, unless otherwise stated in a credit line to the data. 


\section{Background}

High quality healthcare can ensure social justice and preserve client dignity [1]. The multidimensional aspects of healthcare provision are receiving increasing attention within the framework of healthcare quality determined by the World Health Organization (WHO) [2]. Nowadays, patient satisfaction is one of the major outcomes in healthcare and its assessment is considered a very important indicator of healthcare quality [3, 4].

According to WHO guidelines, not only should childbirth be safe, but it should also provide a pleasant experience for all women regardless of their socioeconomic condition. Care during labour and childbirth should be woman-centred and be provided for women and newborns based on a comprehensive approach that is evidence-based and in line with human rights [5].

Through creating a negative experience of childbirth, dissatisfaction with childbirth can induce many problems such as woman psychological disorders, disrupted parent-child relations, severe fear of childbirth, sexual dysfunction [6], disrupted husband-wife relations, post-traumatic stress disorder [7], and reduced inclination to have another child or long intervals between pregnancies [8].

The reported proportion of childbirth satisfaction are varied in different countries; $82 \%$ in Australia [9], 52\% in South Africa [10], 88\% in Ethiopia [11], 21\% in Eritrea [12] and 63\% in Iran [13]. Difference in the assessment method may have affected the results. However, childbirth satisfaction is a complex and multidimensional construct influenced by various factors. Therefore, the variation can be attributed to the differences in women's expectations and quality of care, including the caregiver's emotional support for women, the patient-physician relationship, encouragement received by women from the midwife or the physician and active involvement of women in decision-making about childbirth [14-16].

In some studies, a high level of childbirth satisfaction was also associated with low educational attainment [10, 11], positive attitude to childbirth [17], planned pregnancy, women's knowledge of the stages of labour, lower labour pain intensity [18], administration of analgesics during labour [19], short labour [9], and childbirth by cesarean section [20]. However, the studies are limited and there are contradictory results about the associated factors. For example, in a study conducted in Italy, the results showed that women with a higher level of educational attainment undergoing vaginal birth were more satisfied with childbirth compared to less educated ones [21]; or a study conducted in Iran indicated that there was no correlation between mode of childbirth and level of satisfaction [22]. Also, in most of the previous studies, only a few number of possible risk factors have been investigated.
The most effective and least costly way of providing better and more suitable services is to find factors that influence patient dissatisfaction and attempt to eliminate them [4]. Therefore, considering the lack of sufficient evidence, we aimed to determine the riskand predictive- factors of low childbirth satisfaction using an integrated and collaborative pre- and duringlabour factors to help formulate more effective intervention strategies to improve women's satisfaction with childbirth.

\section{Methods}

This paper was extracted from a more extensive prospective case-control study entitled "birth satisfaction and predictors of prolonged labor" in which women with labour dystocia (cases) were compared with those with no dystocia (controls). Most of possible risk factors were assessed before identification of the dystocia.

In this prospective analytical study, data about most of possible predictors was collected during labour and data about childbirth satisfaction was gathered $12-24 \mathrm{~h}$ postpartum. Participants were selected from two hospitals (Taleghani and Al-Zahra), the only teaching maternal hospitals in Tabriz. With a population of 1.8 million, it is the sixth most populous city in Iran and is the capital city of East Azerbaijan province [23]. Taleghani is a tertiary hospital for referral from other centres in the province and Al-Zahra is a tertiary specialised gynaecology and obstetrics hospital for referral from other centres in the province, and also from nearby provinces with a total population of about 10 million [23]. The childbirth rate in each of these hospitals is about 500 births per month. In Iran, the majority (96.7\%) of births occur in hospitals [24].

In these hospitals, an intravenous cannula was inserted on admission of women to the delivery room, with Ringer's solution infusion commenced only upon physician orders, usually for labour induction or augmentation of labour. Remifentanil in low dose $(0.01$ to $0.03 \mu \mathrm{g} /$ $\mathrm{kg} / \mathrm{min}$ ) was administered in case of normal foetus cardiogram and a minimum cervical dilatation of $5 \mathrm{~cm}$, after obtaining the informed written consent from participants. The foetal heart and uterine contractions were regularly monitored with cardiotocogram devices and participants could mobilise out of bed for short periods of time. The participants had access to food and/or drink (based on stage of labour); however, since participants were lying on the bed and could not have a companion, and there was not enough staff, they were usually not given adequate liquids. In every shift, one midwife was responsible for caring two to three participants, and to observe foetal heart and uterine contraction. The obstetrics residents had direct responsibility for examinations and prescriptions during labour and 
delivery. The vaginal births were carried out by obstetrics residents, interns, midwifery students, or midwives.

Inclusion criteria were healthy women with a singleton uncomplicated pregnancy who were hospitalized for vaginal delivery with fetus in cephalic presentation and gestational age of 370-416 and had history of less than three births. Women with planned cesarean section (Csection), history of C-section at previous pregnancies, pre-labor contraindications for vaginal birth, and any abnormality in bone or soft tissues in pelvic cavity were excluded. Only those with emergency C-sections who were at least $3 \mathrm{~h}$ hospitalized in the labor room were included.

Participants were recruited at the labour wards, by completing the eligibility checklist through interview and vaginal examination (to determine cervical dilation, foetal presentation, and abnormality of pelvic). Written informed consent was obtained from all participants. To assure that women are definitely informed about content of the consent form, at first the investigator ( $\mathrm{PhD}$ student, a highly experienced midwife) briefly explained contents of the form to each participant. Then, she gave them enough time to study the form and consult with family members through phone if needed. The investigator asked participants about the main parts of the form to ensure their understanding before they signed the consent form. Also, at time of collection of data about birth satisfaction, i.e.12-24 h after birth, the investigator got oral informed consent from all participants. If the woman age was under 16 years, written informed consent was also obtained from their husbands before data collection.

The socio-demographic questionnaire (Appendix 1), anxiety state inventory and dehydration checklist were completed at cervical dilatation of $4-6 \mathrm{~cm}$ using the medical records, interview with the women, or examination. The interviews were done between uterine contractions when the woman was relax.

The data extracted from the records were age, parity and gestational age. The other socio-demographic were collected through interview with the women including: education, employment, perceived sufficiency of household income, intention to pregnancy, attendance at birth preparation classes, smoking, alcohol consumption, positive experience of emotional, physical, and sexual violence during pregnancy, and preference of birth method. Experience of emotional, physical and sexual violence during pregnancy was assessed with three questions (one for each), with three "never", "sometimes", and "most often", options. During analysis, the "sometimes" and "most often" responses were combined and was considered as positive experience of violence.

The Spielberger's state anxiety inventory was used to measure anxiety state, which is a 20 -item scale with total score range of 20-80. Scores 20-40 are regarded as mild anxiety, $41-54$ as moderate anxiety, and $\geq 55$ as severe anxiety [25]. Fear was assessed using question no.9 "I feel frightened" in the Spielberger scale. Options "not at all" and "somewhat" were considered as low fear, and options "moderately so" and "very much so" as high fear. For adults, it takes about $10 \mathrm{~min}$ to complete the full 40item state-trait anxiety inventory [26]. Considering the study situation, which we had to discontinue the interviews when the participants had uterine contraction or severe pain, we used only state anxiety inventory which took in average about $10 \mathrm{~min}$ to be completed.

Dehydration was diagnosed by examining for the following signs and symptoms: dry mouth and lips, thirst, difficult speaking due to a sticky dry feeling in the mouth, and difficult swallowing [27]. Existence of any of the symptoms lasted more than $30 \mathrm{~min}$ or any of the signs was regarded as "dehydration". In case of diagnosis of dehydration, the women were given liquids.

The labour progression checklist was completed during labour, with labour dystocia diagnosed using Zhang's guideline [28]. Labour interventions, e.g., induction, augmentation, and administration of remifetanil were completed via observation.

Birth satisfaction and views about staff support was assessed $12-24 \mathrm{~h}$ post childbirth. The 10-item Iranian (Persian) version of the birth satisfaction scale (IP-BSS, Appendix 2) was used to assess birth satisfaction, which is scored using a five-point Likert scale (0 to 4). Total scores range from 0 to 40 , with higher scores representing greater birth satisfaction [29]. The IP-BSS-R has been validated using data from this study and the results were presented in another paper. Original version of the scale was developed in the UK in 2014 [29]. It is now internationally considered the instrument of choice for assessing birth satisfaction [30] and various versions of it have been validated, including the US-BSS-R [31], Greek-BSS-R [32], Turkish-BSS-R [33], Australian-BSS-R [34], Italian-BSS-R [35], and Spanish-BSS-R [36]. The two subscales (satisfaction with doctor and nurse-midwife, items 17-33) of the Mackey childbirth satisfaction rating scale [37] was used to measure staff support. The Mackey scale has been already validated in Iran [38].

Validity of demographic characteristics and labour progression checklist were determined using content validity. Before study commencement, test-retest reliability was evaluated for sensitive socio-demographic data such as domestic violence, sufficiency of household outcome, also for the Mackay and IP-BSS-R scales by asking the related questions twice from 20 women with $14 \pm 2$ day interval. The first assessment was conducted at the same time-point when data for the main study was collected (socio-demographic data at cervical dilatation of 4-6 cm and the Mackay and IP-BSS-R $12-24 \mathrm{~h}$ post childbirth) 
using face-to-face interview and the re-test data was collected through phone interview. Kappa and intra-class correlation (ICC) coefficients calculated for the qualitative and quantitative variables, respectively, were higher than 0.90 in all of them. Internal consistency was measured for the scales using the Cronbach's alpha coefficient, which were found to be satisfactory; $\alpha=0.94$ for the Spielberger state anxiety inventory, $\alpha=0.97$ for nurse and physician sub-scales of the Mackay satisfaction scale, and $\alpha=0.96$ for the IP-BSS-R. Also, correlation of IPBSS-R scores for data collected at the $12-24 \mathrm{~h}$ and $40-$ 45 days after birth for the first 210 participants was strong (0.91). As reported in another paper in detail, most other validity measurements were also conducted for the IP-BSS-R, which all confirmed the tool validity to assess birth satisfaction.

\section{Sample size and statistical analysis}

For linear regression equations using six or more predictors, a minimum of 10 participants per predictor variable are required. However, about 30 participants per variable provide better power to detect a small effect size [39]. Therefore, the $(n=700)$ sample in this study was sufficient to detect more than 20 possible predictive variables, even variables with small effect size.

Data was analyzed using SPSS-version 21 (SPSS, Chicago, IL, USA). Normal distribution of the birth satisfaction score was confirmed using skewness or kurtosis. The univariate general linear model was used to examine the relationship between each probable predictive variable with the overall birth satisfaction score. To determine pre-labour, during-labour and overall predictors of birth dissatisfaction, after creating dummy variables for qualitative variables with more than two options, all of the variables with $p<0.2$ in the unadjusted general linear models were entered into multiple linear models with backward strategy. Sidak was used to adjust for the multiple comparisons. Linear regression assumptions such as normality of residuals and no perfect multicollinearity were checked before applying the models. Adjusted R squared was calculated to determine the proportion of the variation in the score explained by the independent variables.

\section{Results}

\section{Participant characteristics}

Data was collected between Oct 2018 and Jun 2019. 26 out of the 700 women were detected as multivariate outliers using Mahalanobis distances [40] and therefore were excluded from analysis. Among the 674 remaining women, 340 (50.4\%) were from Taleghani hospital, 382 (57\%) were primiparous. 41 (6.1\%) had emergency Csection which all was conducted by the residents. Among those with vaginal delivery, majority $(86 \%)$ were attended by the residents, $11 \%$ by midwifery students and $3 \%$ by midwives. There was no instrumental childbirth. Labour induction was conducted in $43 \%$ of participants and episiotomy in majority of those with vaginal births (95\% in primiparous and 67\% in multiparous). None of the women reported the use of water pipe or alcohol during their pregnancy and only one woman reported tobacco smoking during pregnancy. Only 5 women were employed. The mean age of the women was 26.1 (SD 6.4) years. Mean score of the total satisfaction score was 23.85 (SD 6.48).

\section{Association of the pre- and during- labor factors with the birth satisfaction score}

In the unadjusted analysis, the pre-labour variables which correlated with low birth satisfaction score included: insufficient household income, being primiparous, no attendance at birth preparation classes, experience of emotional and sexual violence during pregnancy, women's preference for C-section, and gestational age of $40^{\circ}$ weeks or more. The during-labour variables were: dehydration, labour induction and labour augmentation with oxytocin, abnormal fetal cardiogram, receiving remifentanil, labour dystocia, high fear, moderate or severe anxiety state, insufficient support by staff, vaginal birth with episiotomy and/or tear, emergency C-section, and no breast feeding at 1 st hour post childbirth. There was no significant differences between women of diverse age, educational levels, with or without planned pregnancy, and with or without experience of physical violence, in relation to satisfaction score (Table 1).

\section{Pre- labour predictors of birth satisfaction score}

The predictors included being primiparous $(\beta=-0.215)$, sexual $(\beta=-0.179)$ and emotional $(\beta=-0.105)$ violence during pregnancy, gestational age more than 40 weeks $(\beta=-0.138)$, woman preference for caesarean section $(\beta=-112)$, no attendance at birth preparation classes $(\beta=-0.096)$, insufficient household income $(\beta=-$ $0.084)$. The proportion of variation in the satisfaction score explained by these independent variables was $14 \%$ (Table 2).

\section{During-labour predictors of low birth satisfaction score}

There was collinearity between fear and anxiety factors. Therefore, we conducted two models: 1) 1) with excluding factor of woman fear, 2) with excluding factor of woman anxiety.

Excluding factor of woman fear, the predictors included severe $(\beta=-0.455)$ and moderate $(\beta=-0.236)$ anxiety state, labour dystocia $(\beta=-0.391)$, insufficient support by staff $(\beta=-139)$, vaginal birth with episiotomy and tear $(\beta=-0.139)$, emergency $C$-section $(\beta=-$ 0.113), labour induction with oxytocin $(\beta=-0.098)$, 
Table 1 Birth satisfaction score by pre- and during- labour factors ( $n=674$ )

\begin{tabular}{|c|c|c|c|c|c|c|c|}
\hline Pre-labour Factors & $n$ & Mean (SD) & Mean difference & During labour factors & $n$ & Mean (SD) & $\mathrm{MD}(95 \% \mathrm{Cl})$ \\
\hline \multicolumn{4}{|l|}{ Hospital } & \multicolumn{4}{|l|}{ Woman dehydration $^{\mathrm{b}}$} \\
\hline Taleghani & 340 & $23.8(6.6)$ & $-0.02(-1.0$ to 1.0$)$ & No & 350 & $26.4(5.9)$ & reference \\
\hline Al-zahra & 334 & $23.9(6.3)$ & reference & Less than $3 \mathrm{~h}$ & 266 & $21.8(6.0)$ & $-4.6(-5.7 \text { to }-3.2)^{* * * *}$ \\
\hline \multicolumn{4}{|l|}{ Age (year) } & More than $3 \mathrm{~h}$ & 58 & $18.0(4.1)$ & $-8.4(-10.3 \text { to }-6.4)^{* * * *}$ \\
\hline$\leq 20$ & 116 & $24.1(5.8)$ & $0.3(-1.0$ to 1.9$)$ & \multicolumn{4}{|c|}{ Labour Induction with oxytocin } \\
\hline $21-34$ & 477 & $23.8(6.5)$ & reference & No & 384 & $27.0(5.6)$ & reference \\
\hline $35+$ & 81 & $24.0(7.1)$ & $0.2(-2.0$ to 1.7$)$ & Yes & 290 & $19.7(5.0)$ & $-7.3(-8.1 \text { to }-6.5)^{* * *}$ \\
\hline \multicolumn{4}{|l|}{ Woman education $^{\mathrm{a}}$} & \multicolumn{4}{|c|}{ Labour Augmentation with oxytocin } \\
\hline No or low & 372 & $24.1(6.4)$ & reference & No & 196 & $28.9(4.7)$ & reference \\
\hline High & 302 & $23.6(6.6)$ & $-0.5(-1.5$ to 0.5$)$ & Yes & 478 & $21.7(5.9)$ & $-7.2(-8.2 \text { to }-6.3)^{* * *}$ \\
\hline \multicolumn{4}{|c|}{ Views on household Income } & \multicolumn{4}{|l|}{ Amniotomy } \\
\hline Sufficient & 304 & $24.7(6.6)$ & reference & No & 357 & $24.5(6.6)$ & reference \\
\hline Insufficient & 370 & $23.2(6.3)$ & $-1.5(-2.5 \text { to }-0.5)^{* *}$ & Yes & 317 & $23.1(6.2)$ & $-1.4(-2.4 \text { to }-0.4)^{* *}$ \\
\hline \multicolumn{4}{|l|}{ Parity } & \multicolumn{4}{|c|}{ Abnormal fetal cardiogram } \\
\hline Primiparous & 382 & $23.1(6.2)$ & $-1.8(-2.8 \text { to }-0.9)^{* * *}$ & No & 653 & $24.0(6.5)$ & reference \\
\hline Multiparous & 292 & $24.9(6.7)$ & reference & Yes & 21 & $19.4(5.5)$ & $-4.6(-7.4 \text { to }-1.8)^{* *}$ \\
\hline \multicolumn{4}{|l|}{ Planned pregnancy } & \multicolumn{4}{|l|}{ Receive remifentanil } \\
\hline Yes & 558 & $24.1(6.4)$ & reference & No & 557 & $24.3(6.4)$ & reference \\
\hline No & 116 & $23.8(6.5)$ & $0.3(-1.0$ to 1.6$)$ & Yes & 117 & $21.5(6.4)$ & $-2.81(-4.1 \text { to }-1.5)^{* * * *}$ \\
\hline \multicolumn{4}{|c|}{ Attendance at birth preparation classes } & \multicolumn{4}{|l|}{ Labour dystocia } \\
\hline Yes & 70 & $25.4(6.2)$ & reference & No & 335 & $28.8(4.1)$ & reference \\
\hline No & 604 & $23.7(6.5)$ & $-1.7(-3.4 \text { to }-0.1)^{*}$ & Yes & 339 & $18.9(4.2)$ & $-9.9(-10.6 \text { to }-9.3)^{* * *}$ \\
\hline \multicolumn{4}{|c|}{ Woman experience of violence during pregnancy } & \multicolumn{4}{|l|}{ Fear $^{c}$} \\
\hline \multicolumn{4}{|l|}{ Physical violence } & Low & 285 & $28.7(4.9)$ & reference \\
\hline No & 618 & $24.0(6.5)$ & reference & High & 389 & $20.3(5.1)$ & $-8.4(-9.2 \text { to }-7.6)^{* * *}$ \\
\hline Yes & 56 & $22.4(6.4)$ & $-1.6(-3.3$ to 0.2$)$ & \multicolumn{4}{|l|}{ Anxiety state ${ }^{c}$} \\
\hline \multicolumn{4}{|l|}{ Emotional violence } & Mild & 232 & $30.2(3.6)$ & reference \\
\hline No & 484 & $24.6(6.3)$ & reference & Moderate & 175 & $23.9(4.9)$ & $-6.2(-7.2 \text { to }-5.3)^{* * * *}$ \\
\hline Yes & 190 & $21.9(6.5)$ & $-2.7(-3.7 \text { to }-1.6)^{* * *}$ & Severe & 267 & $18.3(3.7)$ & $-11.8(-12.7 \text { to }-11.0)^{* * * * *}$ \\
\hline \multicolumn{4}{|l|}{ Sexual violence } & \multicolumn{4}{|l|}{ Support by staff ${ }^{\triangleright}$} \\
\hline No & 600 & $24.4(6.4)$ & reference & Insufficient & 109 & $16.4(3.4)$ & $-8.8(-10.0 \text { to }-7.7)^{* * * *}$ \\
\hline Yes & 74 & $19.4(5.4)$ & $-5.0(-6.5 \text { to }-3.5)^{* * *}$ & Sufficient & 565 & $25.3(5.9)$ & reference \\
\hline \multicolumn{4}{|c|}{ Woman preference of birth } & \multicolumn{4}{|l|}{ Mode of childbirth } \\
\hline Vaginal or no matter & 578 & $24.3(6.4)$ & reference & Vaginal with no epi/tear & 85 & $27.2(5.8)$ & reference \\
\hline Cesarean & 96 & $21.1(6.0)$ & $-3.2(-4.6 \text { to }-1.9)^{* * * *}$ & Vaginal with epi or tear & 507 & $24.2(6.2)$ & $-2.9(-4.8 \text { to }-1.0)^{* * * *}$ \\
\hline \multicolumn{4}{|c|}{ Gestational age (weeks) } & Vaginal with epi and tear & 41 & $18.9(5.5)$ & $-8.2(-11.2 \text { to }-5.2)^{* * * *}$ \\
\hline $37^{0}$ to $39^{6}$ & 427 & $24.5(6.4)$ & reference & Emergency CS & 41 & $16.9(4.0)$ & $-10.3(-13.3 \text { to }-7.3)^{* * *}$ \\
\hline \multirow[t]{3}{*}{$40^{\circ}$ or more } & 247 & $22.7(6.4)$ & $-1.77(-2.8 \text { to }-0.8)^{* *}$ & Breast feeding at $1 \mathrm{st} \mathrm{h} \mathrm{a}$ & child & & \\
\hline & & & & Yes & 618 & $24.2(6.4)$ & reference \\
\hline & & & & No & 56 & $20.3(5.6)$ & $-4.2(-5.9 \text { to }-2.4)^{* * *}$ \\
\hline
\end{tabular}

epi Episiotomy, CS Cesarean section, * $P<0.05,{ }^{* *} P<0.005$, *** $P<0.001$

All analysis were done using univariate general linear model

Birth satisfaction was assessed by Iranian (Persian) version of the birth satisfaction scale-revised (IP-BSS-R) with range score of 0-40 (the higher score, the higher satisfaction)

a 15 were illiterate, 357 had low education (153 had elementary, 204 Junior high school/guidance), 240 senior high school and 62 university education, bexistence of one of dehydration signs or symptoms (dry mouth and lips, thirst, dizziness, weakness, trouble swallowing dry food, dry, sticky mouth that makes it hard to talk, a swollen, cracked or dry tongue) [27] . 'Anxiety was assessed using the Spielberger's State Anxiety Inventory (scores 20-40: mild, 41-54: moderate, $\geq 55$ : severe anxiety). Fear was assessed using one question "I feel frightened" with four options (not at all/somewhat: low fear, moderately so/very much so: high fear [25]. Staff support was assessed using nurse and physician subscale of Mackey satisfaction tool (score range:17-85, scores 51 or less: insufficient, 52 or more: good support [37] 
vaginal birth with episiotomy or tear $(\beta=-0.055)$, and women dehydrated for more than $3 \mathrm{~h}(\beta=-0.058)$ and less than $3 \mathrm{~h}(\beta=-0.045)$. The proportion of variation in satisfaction scores explained by these independent variables was 75\% (Table 2).

Excluding factor of woman anxiety, the predictors included the above ones (with small changes in their $\beta$ ) in addition to high fear $(\beta=-0.239)$, and labour augmentation with oxytocin $(\beta=-0.076)$. The proportion of variation in satisfaction scores explained by these independent variables was $72 \%$ (Table 2).

\section{Overall predictors of low birth satisfaction score}

Excluding factor of woman fear, the predictors included severe $(\beta=-0.426)$ and moderate $(\beta=-0.222)$ anxiety state, labour dystocia $(\beta=-0.324)$, insufficient support by staff $(\beta=-0.157)$, vaginal birth with episiotomy and tear $(\beta=-0.109)$, emergency $C$-section $(\beta=-0.076)$, being primiparous $(\beta=-0.093)$, labour induction with oxytocin $(\beta=-0.088)$, sexual violence $(\beta=-0.060)$, and women dehydrated for more than $3 \mathrm{~h}(\beta=-0.047)$ and less than $3 h(\beta=-0.036)$. The proportion of variation in satisfaction score explained by all these factors was $76 \%$ (Table 2).

Excluding factor of woman anxiety, predictors included the above ones in addition to high fear $(\beta=-$ $0.239)$, and labour augmentation with oxytocin $(\beta=-$ $0.079)$. The proportion of the variation in satisfaction score explained by all these factors was $72 \%$ (Table 2).

\section{Discussion}

The quite high proportion (75\%) of variation in satisfaction scores are explained by the during-labour variables, which include severe and moderate anxiety state, labour dystocia, insufficient support by staff, vaginal birth with episiotomy and tear, emergency C-section, labour induction and augmentation with oxytocin, and dehydration. Replacing the factor of anxiety state (assessed by 20 items) with fear (assessed by one item) does not change considerably the proportion. Pre-labour predictors include being primiparous and experiencing sexual and/or emotional violence during pregnancy, gestational age of $40^{\circ}-41^{6}$ weeks, woman preference for C-section, no attendance at birth preparation classes, and insufficient household income explain only $14 \%$ of the variation in satisfaction score. Adding the pre-labour predictors to the during-labour predictors does not increase the explanation proportion.

In overall, results of the current study are in agreement with the literature review, which indicate that supporting women during birth, minimal interventions, and birth preparedness are successful strategies for creating positive perceptions of childbirth [41]. A systematic review also shows that the during-labour factors such as the amount of support from caregivers and the quality of the caregiver-client relationship are more important factors influencing on birth satisfaction compared to some pre-labour factors such as age, socioeconomic status and childbirth preparation [42].

Using the BSS-R scale, mean birth satisfaction score in this study (23.8, SD 6.5) was lower than that in most studies in other countries such as US (32.4, SD 6.4) [31], Australia (30.4, SD 5.9) [34], UK (28.4, SD 5.6) [29], Spain (28.1, SD 6.2) [36], and Greece (27.4, SD 6.2) [32] but was higher than that in Turkey (20.4, SD 6.0) [33]. The high medicalized birth management in Iran may be an important reason for the lower birth satisfaction in the study setting compared to many of the other studies.

Although, WHO recommends that routine or liberal use of episiotomy should not be used for women undergoing spontaneous vaginal birth [5], it was routinely used in the study setting. But in most of abovementioned countries it is used selectively. For example, its reported rate in a national survey in the US was 25\% in 2004 [43] and in a recent study in two largest maternity public hospitals in Greece was 17\% [44]. Similar with Iran, episiotomy rate in Turkey is also high (93\% in primiparous and $30 \%$ in multiparous women) [45]. In the current study, both episiotomy with or without a tear was associated with low satisfaction. Third degree perineal tear was also identified as an important predictive factor in a study in Canada [46]. Higher pain and discomfort following episiotomy especially extended one may affect women's perceptions of disturbances to the structure of their reproductive organs and perceived potential for future enjoyment of sex [47].

In tertiary level teaching hospitals in Iran, most deliveries are attended by obstetrics residents. In our study, only $14 \%$ of births were attended by midwives or midwifery students. Studies show that birth attendance by skilled motivated midwives could improve more than 50 maternal and neonatal outcomes including reduced anxiety during labour and satisfaction with childbirth experience [48]. According to the Cochran review, women who received midwife-led continuity models of care were less likely to experience intervention and more likely to be satisfied with their care than those who received other models of care [49]. Therefore, WHO emphasizes on providing care based on the midwife-led models for promoting birth satisfaction [5].

In this study, severe anxiety state was the strongest predictor, and moderate anxiety was a strong predictor of low satisfaction. A possible explanation is the relationship of high anxiety with feeling of no or low personal control during labour and birth [50] and relationships of low personal control with maternal birth dissatisfaction [37, 51]. Another explanation could be the positive relationship of high anxiety state with more 
Table 2 Pre-labour and during labour factors predictors of dissatisfaction of childbirth $(n=674)$

\begin{tabular}{|c|c|c|c|c|c|c|}
\hline Predictors & Beta & B $(95 \% \mathrm{Cl})$ & $\mathrm{P}$ & Beta & B (95\% Cl) & $P$ \\
\hline \multicolumn{7}{|l|}{ 1. Pre-labour predictors ${ }^{*}$} \\
\hline Constant & - & 29.7 (27.9 to 31.5$)$ & $<0.001$ & - & - & - \\
\hline Primiparous & -0.215 & $-2.8(-3.8$ to -1.8$)$ & $<0.001$ & - & - & - \\
\hline Sexual violence during pregnancy & -0.179 & $-3.7(-5.4$ to -2.0$)$ & $<0.001$ & - & - & - \\
\hline Gestational age of $40^{0}-41^{6} \mathrm{~W}$ (Ref: $\left.37^{0}-39^{6}\right)$ & -0.138 & $-1.9(-2.8$ to -0.9$)$ & $<0.001$ & - & - & - \\
\hline Woman preference for Cesarean section & -0.112 & $-2.1(-3.6$ to -0.5$)$ & 0.003 & - & - & - \\
\hline Emotional violence during pregnancy & -0.105 & $-1.5(-2.7$ to -0.3$)$ & 0.012 & - & - & - \\
\hline No attendance at birth preparation classes & -0.096 & $-2.0(-3.6$ to -0.5$)$ & 0.009 & - & - & - \\
\hline Perceived insufficient household income & -0.084 & $-1.1(-2.1$ to -0.1$)$ & 0.025 & - & - & - \\
\hline 2. During-labour predictors $\dagger$ & \multicolumn{3}{|c|}{ Excluded woman fear } & \multicolumn{3}{|c|}{ Excluded woman anxiety state } \\
\hline Constant & - & 31.4 (30.7 to 32.2 ) & $<0.001$ & - & 31.6 (30.7 to 32.4$)$ & $<0.001$ \\
\hline Sever anxiety state (Ref: mild) & -0.455 & $-6.0(-6.9$ to -5.2$)$ & $<0.001$ & - & - & - \\
\hline Labour dystocia & -0.301 & $-3.9(-4.7$ to -3.1$)$ & $<0.001$ & -0.382 & $-4.9(-5.7$ to -4.1$)$ & $<0.001$ \\
\hline High fear & - & - & - & -0.239 & $-3.1(-3.8$ to -2.5$)$ & $<0.001$ \\
\hline Moderate anxiety state (Ref: mild) & -0.236 & $-3.5(-4.2$ to -2.8$)$ & $<0.001$ & - & - & - \\
\hline Insufficient support by staff & -0.139 & $-2.7(-3.4$ to -1.9$)$ & $<0.001$ & -0.177 & $-3.1(-3.91$ to -2.3$)$ & $<0.001$ \\
\hline \multicolumn{7}{|c|}{ Mode of Birth (Ref: vaginal with no episiotomy/no tear) } \\
\hline Vaginal birth with episiotomy and tear & -0.139 & $-3.8(-4.9$ to -2.5$)$ & $<0.001$ & -0.158 & $-4.3(-5.6$ to -3.0$)$ & $<0.001$ \\
\hline Emergency cesarean section & -0.113 & $-2.9(-4.2$ to -1.7$)$ & $<0.001$ & -0.134 & $-3.5(-4.8$ to -2.2$)$ & 0.001 \\
\hline Vaginal birth with episiotomy or tear & -0.055 & $-0.8(-1.6$ to -0.1$)$ & 0.034 & -0.064 & $-1.0(-1.8$ to -0.1$)$ & 0.021 \\
\hline Labour induction with oxytocin & -0.098 & $-1.3)-1.9$ to -0.7$)$ & $<0.001$ & -0.103 & $-1.3)-2.0$ to -0.7$)$ & $<0.001$ \\
\hline Labour augmentation with oxytocin & - & - & - & -0.076 & $-1.1(-1.8$ to -0.3$)$ & 0.004 \\
\hline \multicolumn{7}{|l|}{ Woman dehydration (Ref: no dehydration) } \\
\hline Dehydration $+3 \mathrm{~h}$ & -0.058 & $-1.3(-2.3$ to -0.3$)$ & 0.008 & -0.073 & $-1.7(-2.7$ to -0.7$)$ & 0.002 \\
\hline Dehydration $<3 \mathrm{~h}$ & -0.045 & $-0.6(-1.2$ to -0.03$)$ & 0.039 & -0.045 & $-0.6(-1.2$ to 0.01$)$ & 0.053 \\
\hline 3. Overall predictors ${ }^{\ddagger}$ & \multicolumn{3}{|c|}{ Excluded woman fear } & \multicolumn{3}{|c|}{ Excluded woman anxiety state } \\
\hline Constant & - & 31.4 (30.8 to 31.8$)$ & $<0.001$ & - & 31.3 (30.8 to 31.9 ) & $<0.001$ \\
\hline Severe anxiety state (Ref: mild) & -0.426 & $-5.6(-6.5$ to -4.8$)$ & $<0.001$ & - & - & - \\
\hline Labour dystocia & -0.324 & $-4.2(-5.0$ to -3.4$)$ & $<0.001$ & -0.414 & $-5.4(-6.15$ to -4.6$)$ & $<0.001$ \\
\hline Moderate anxiety state (Ref: mild) & -0.222 & $-3.3(-4.0$ to -2.6$)$ & $<0.001$ & - & - & - \\
\hline High fear & - & - & - & -0.239 & $-2.8(-3.4-$ to -2.1$)$ & $<0.001$ \\
\hline Insufficient support by staff & -0.157 & $-2.7(-3.5$ to -2.0$)$ & $<0.001$ & -0.183 & $-3.2(-3.10$ to -2.4$)$ & $<0.001$ \\
\hline \multicolumn{7}{|c|}{ Mode of Birth (Ref: vaginal with no episiotomy/no tear) } \\
\hline Vaginal birth with episiotomy and tear & -0.109 & $-2.9(-3.9$ to -1.9$)$ & $<0.001$ & -0.123 & $-3.3(-4.4$ to -2.3$)$ & $<0.001$ \\
\hline Emergency caesarean section & -0.076 & $-2.0(-3.0$ to -1.0$)$ & $<0.001$ & -0.088 & $-2.3(-3.3$ to -1.2$)$ & $<0.001$ \\
\hline Primiparous & -0.093 & $-1.2(-1.7$ to -0.7$)$ & $<0.001$ & -0.105 & $-1.4(-1.9$ to -0.8$)$ & $<0.001$ \\
\hline Labour induction & -0.088 & $-1.1)-1.7$ to -0.5$)$ & $<0.001$ & -0.098 & $-1.3)-2.0$ to -0.6$)$ & $<0.001$ \\
\hline Labour augmentation & - & - & - & -0.079 & $-1.1(-1.8$ to -0.4$)$ & 0.002 \\
\hline Sexual violence during pregnancy & -0.060 & $-1.2(-2.1$ to -0.4$)$ & 0.003 & -0.062 & $-1.3(-2.2$ to -0.4$)$ & 0.004 \\
\hline Woman dehydration $+3 \mathrm{~h}$ (Ref: no dehydration) & -0.047 & $-1.1(-2.1$ to -0.1$)$ & 0.029 & -0.049 & $-1.1(-2.1$ to -0.2$)$ & 0.022 \\
\hline Woman dehydration < $3 \mathrm{~h}$ (Ref: no dehydration) & -0.036 & $-0.5(-1.1$ to 0.07$)$ & 0.099 & - & - & - \\
\hline
\end{tabular}

Birth satisfaction was assessed by Iranian (Persian) version of the birth satisfaction scale-revised (IP-BSS-R) with range score of 0-40 (the higher score, the higher satisfaction)

All analysis were done using multiple linear regression model with backward strategy. Sidak was used to adjust for the multiple comparisons

* Adjusted for all other pre-labour variables with a relation of $p<0.2$ in the univariate analysis (variables of attendance at pregnancy classes, parity, history of abortion, interval between previous childbirth, household income, planned pregnancy and physical violence were removed from the model). adjusted $R^{2}=0.137$ † Adjusted for all during labour variables with a relation of $p<0.2$ in the univariate analysis (variables of woman dehydration, labour augmentation, amniotomy, amnion sac status, fetal cardiogram condition, administeration of remifentanil and time of breastfeeding were removed from the model. Adjusted $R^{2}=0.749$ when excluded fear and adjusted $R^{2}=0.717$ when excluded woman anxiety variable

‡ Adjusted for all variables entered in the above models. Adjusted $R^{2}=0.756$ when excluded fear and adjusted $R^{2}=0.725$ when excluded woman anxiety variable 
severe labour pain [52], and relationships of experiencing pain with dissatisfaction [37].

The result of high fear as a strong predictor of low satisfaction, could be considered consistent with the study conducted with Swedish and Australian women [53], which indicate that fearful women experience psychological distress significantly increases chances of having a negative childbirth experience. Other studies also indicate high fear of birth as predictive factor of negative birth experience [54-56]. Childbirth satisfaction and childbirth experience are highly correlated [57].

In our study, labour dystocia was a strong predictor of low satisfaction, which is in keeping with other study results $[46,58]$. Prolonged birth was identified as a predictive factor of birth satisfaction in Canada [46] and as an associated factor in a Swedish study [58]. Administration of medical interventions and having severe labour pain which are associated with labour dystocia may have been one cause of low satisfaction.

Similar results about insufficient support from midwife/nurse and/or physician, as a strong predictor of low childbirth satisfaction, is also reported in other studies $[10,11]$. Also, in a systematic review it was indicated that perceived unhelpfulness of care providers is a predictor of childbirth dissatisfaction [42].

In a Swedish study, emergency C-section was the strongest predictor of childbirth dissatisfaction [59]. Yet in our study it was an important predictor, but not the strongest one, with its effect weight less than vaginal delivery with episiotomy and tear (extended episiotomy). This may have been related to Iranian women having a higher preference for $\mathrm{C}$-section compared to Swedish women. In Sweden, 7\% of pregnant women reported a preference for having a C-section [60]. But in the present study which those with planned Csection were not included, it was $14 \%$. In another Iranian study, the preference was 32\% [61]. C-section rate in Sweden is $17.4 \%$ while in Iran is $45.6 \%$ [62]. High education, fear of vaginal birth and doctor's recommendation have been mentioned as the most non-obstetric factors influencing on the high Csection rate in the country [63].

Our results are also consistent with previous studies which show associations between labour induction and augmentation with low satisfaction [59] and negative birth experience $[58,64]$. Increased severity of pain from interventions may explain these associations.

In previous studies, obstetric interventions, including emergency C-section [59, 65] and labor induction [59] were significantly related to dissatisfaction with childbirth and negative birth experience. Other factors, such as lack of control, insufficient/no involvement in decision-making, and complications for mother or child may also explain the associations.
Being primiparous was a strong pre-labour predictor of low satisfaction, with its predictive weight reduced considerably in the overall model which included all pre and during-labour factors. Higher anxiety, fear of birth among women with no experience of birth could explain some of this association. Also, only one tenth of participants in the current study attended birth preparation classes. Being primiparous was associated with low birth satisfaction in a US study [65], and Swedish study [58], with a review supporting low birth satisfaction amongst primiparous women [42].

In current study, reported experience of sexual abuse during pregnancy was a strong pre-labour predictive factor of the low satisfaction, which was also included in the overall model. Its weigh was reduced in the overall model in both pre- and during-labour variables (change in beta from -0.179 to -0.071 ). This association may be related to high fear of birth and anxiety among such women. A Norwegian study showed history of abuse was common among women with high fear of birth compared to those with moderate fear (76\% vs 39\%) [66]. Although emotional abuse was associated with low satisfaction, its weight was low in the pre-labour model, and it was not included in the overall model. Studies in Norway [55] and Canada [67] also indicate that a history of abuse is an associated factor with negative birth experience, with type of abuse not reported in these studies.

Limited knowledge exists about the association of dehydration during labour and birth satisfaction. Although in the unadjusted analysis, the mean difference of satisfaction score between women with $>3$ hour compared with those with no dehydration was high $(\beta=-8.4)$. In the adjusted analysis, this factor gained lowest weight amongst all of the predictive factors. Possible reason for this change may be its multicollinearity with other factors. Dehydration may result in some metabolic disorders, which in turn could result in the dysfunction of uterine muscles and prolonged labour [68]. Another possible explanation could be women's perceptions of lack of staff attention to their personal needs.

No other study reported associations between gestational age of $40^{\circ}-41^{6}$ weeks and birth satisfaction. In the current study, this was a pre-labour predictor of low birth satisfaction, yet was removed from the overall model. In the setting of this study, women at gestational age of 40 weeks or more, even with no labour pain, were hospitalized. Long duration of stay in hospital and interventions, such as induction and vaginal examinations, may have resulted in fatigue and increased concern and anxiety, which in turn lowers satisfaction.

Our reports of higher birth satisfaction in those who attended birth preparation classes, is also in line with results of other studies in Iran [69] and other countries 
[70-72]. In a Canadian study, degree of awareness of events during birth was the strongest predictor of women's perceptions [56]. Possible explanations for these relationships, are that education and exercise classes could decrease fear and anxiety [73], increase confidence in ability to cope [70], result in shorter duration of labour [71], and increase ability to push spontaneously [74].

Our associations of insufficient household income and low satisfaction are in keeping with other studies [55, 75 ], with concerns about being able to pay for care and a new infant augmenting reduced satisfaction.

\section{Strengths and limitations}

A strength of this study is that it is one of the first to investigate predictors of birth satisfaction in Iran. Also, the relatively large sample size provided sufficient power to investigate the high number of factors associated with low birth satisfaction, even those factors with a small effect size. Assessing the possible predictive factors before assessment of satisfaction may also have reduced information bias.

Assessing some of the possible risk factors at early stage of active phase of labour might affect the women's ability to participate in an interview and respond correctly to the questions. However, the high skills of the investigator who was an experienced midwife for effective communication with clients prevent the problem. Results of the validation tests such as ICC and Cronbach's alpha also confirmed validity of the collected data.

Assessing birth satisfaction at 12-24 hours post birth and before discharge from hospital could be considered a limitation of this study. However, as reported in the paper, there was a strong correlation $(r=0.91)$ between satisfaction scores assessed at 12-24 hour and at 40-45 days post birth.

Having no information about women's psychological distress, e.g., anxiety before pregnancy and labour, could be a further limitation of this study. Consequently, we cannot judge associations between anxiety during pregnancy and birth satisfaction.

This study was conducted at tertiary teaching settings with many complicated cases referred from other centers where obstetrics residents were the main caregivers during labour and birth. Therefore, the results may not be generalizable to the primary or secondary level settings where midwives are main responsible person for the childbirths and mostly provide services for low risk women or may not be generalizable to the private settings where midwives and obstetricians provide services for the women during labour and birth.
Due to the nature of observational studies, we also cannot consider cause of effects, with further studies to address controllable factors recommended.

\section{Conclusions}

Based on this study results, the during-labour predictors explain most of the variance in childbearing women's birth satisfaction scores. Most predictors of the low childbirth satisfaction, e.g., anxiety, insufficient support from staff during labour, maternal dehydration, and allied interventions are controllable. Appropriate consultation with couple during pregnancy and encouraging to attend birth preparation classes may also reduce some factors such as violence, fear and anxiety.

Hence, responding to women's physical and psychological needs, reducing interventions, meeting women's desire for information during pregnancy and childbirth, and women's involvement in decision making which are in line with woman-centred models of childbirth care, in particular through midwife-led models, could enhance the birth satisfaction.

\section{Supplementary information}

Supplementary information accompanies this paper at https://doi.org/10 1186/s12884-020-03105-5.

\section{Additional file 1.}

Additional file 2.

\section{Abbreviations}

WHO: World health organization; CS: Caesarean section; IP-BSS-R: Iranian (Persian) birth satisfaction scale-revised; Cl: Confidence interval

\section{Acknowledgments}

This article was extracted from a PhD thesis in Tabriz University of Medical Sciences. We would like to thank authorities of the university for the scientific and ethical approval and financial support of this research. We also sincerely thank all participating women, midwives, and delivery room residents for their cooperation in this study.

\section{Authors' contributions}

All of the authors contributed to the conception and design of the study. JN recruited the participants, collected the data, and wrote the first draft of the paper. JN and SMAC, CRM analyzed the data. SMAC, FAA, CRM, CJHM, MM and $\mathrm{HH}$ revised the manuscript. All the authors read and approved the final manuscript.

\section{Funding}

This research was funded by the Research Vice-Chancellor of Tabriz University of Medical Sciences in Iran. The funding center had no role in the design, analysis or writing of this article.

\section{Availability of data and materials}

The datasets used and analysed during the current study are available from the corresponding author on reasonable request.

Ethics approval and consent to participate

The study was approved by the Ethics Committee of Tabriz University of Medical Sciences under the code IR.TBZMED.REC.1397.624. We followed all Helsinki declaration and national ethical standards. All participants were ensured about the matter of confidentiality, and informed written consent of 
the participants, and in case of under 16 years old also from their husbands (and from their parents if accessible), was obtained before data collection.

\section{Consent for publication}

Not applicable.

\section{Competing interests}

The authors declare no competing interests.

\section{Author details}

'Students' Research Committee, Faculty of Nursing and Midwifery, Tabriz University of Medical Sciences, Tabriz, Iran. ${ }^{2}$ Social Determinants of Health Research Center, Department of Midwifery, Faculty of Nursing and Midwifery, Tabriz University of Medical Sciences, Tabriz, Iran. ${ }^{3}$ Women's Reproductive Health Research CenterTabriz University of Medical Sciences, Tabriz, Iran. ${ }^{4}$ Institute for Clinical and Applied Health Research (ICAHR), University of Hull, Hull, UK. ${ }^{5}$ School of Health, Edinburgh Napier University, Edinburgh, UK. ${ }^{6}$ Department of Midwifery, Faculty of Nursing and Midwifery, Tabriz University of Medical Sciences, Tabriz, Iran. ${ }^{7}$ Department of Medical and Surgical Nursing, Faculty of Nursing and Midwifery, Tabriz University of Medical Sciences, Tabriz, Iran.

Received: 22 January 2020 Accepted: 9 July 2020

Published online: 14 July 2020

\section{References}

1. World Health Organization. Standards for improving quality of maternal and newborn care in health facilities. Geneva: WHO; 2016.

2. Tunçalp Ö, Were WM, MacLennan C, Oladapo OT, Gülmezoglu AM, Bahl R, Daelmans B, Mathai M, Say L, Kristensen F, et al. Quality of care for pregnant women and newborns-the WHO vision. BJOG. 2015;122(8):1045-9.

3. Bowman MA, Herndon A, Sharp PC, Dignan MB. Assessment of the patientdoctor interaction scale for measuring patient satisfaction. Patient Educ Couns. 1992;19(1):75-80.

4. Jackson JL, Chamberlin J, Kroenke K. Predictors of patient satisfaction. Soc sci Med. 2001;52(4):609-20

5. World Health Organization. WHO recommendations: intrapartum care for a positive childbirth experience. Geneva: World Health Organization; 2018. https://www.who.int/publications/i/item/9789241550215.

6. Ayers $\mathrm{S}$, Eagle A, Waring $\mathrm{H}$. The effects of childbirth-related post-traumatic stress disorder on women and their relationships: a qualitative study. Psychol Health Med. 2006;11(4):389-98.

7. Fenech $\mathrm{G}$, Thomson $\mathrm{G}$. Tormented by ghosts from their past': a metasynthesis to explore the psychosocial implications of a traumatic birth on maternal well-being. Midwifery. 2014;30(2):185-93.

8. Gottvall K, Waldenstrom U. Does a traumatic birth experience have an impact on future reproduction? BJOG. 2002;109(3):254-60.

9. Bitew K, Ayichiluhm M, Yimam K. Maternal satisfaction on delivery service and its associated factors among mothers who gave birth in public health facilities of Debre Markos town, Northwest Ethiopia. Biomed Res Int. 2015; 2015:460767.

10. Lumadi TG, Buch E. Patients' satisfaction with midwifery services at a regional hospital and its referring clinics in the Limpopo province of South Africa. Afr J Nurs Midwifery. 2011;13(2):14-28.

11. Asres GD. Satisfaction and associated factors among mothers delivered at Asrade Zewude Memorial Primary Hospital, Bure, West Gojjam, Amhara, Ethiopia: a cross sectional study. Prim Health Care. 2018;8(2). https://doi.org/ 10.4172/2167-1079.1000293.

12. Kifle MM, Ghirmai FA, Berhe SA, Tesfay WS, Weldegebriel YT, Gebrehiwet ZT. Predictors of Women's satisfaction with hospital-based Intrapartum Care in Asmara Public Hospitals, Eritrea. Obstet Gynecol Int J. 2017;2017:3717408.

13. Ghanbari-Homayi S, Fardiazar Z, Meedya S, Mohammad-Alizadeh-Charandabi S, Asghari-Jafarabadi M, Mohammadi E, Mirghafourvand M. Predictors of traumatic birth experience among a group of Iranian primipara women: a cross sectional study. BMC Pregnancy Childbirth. 2019;19(1):182.

14. Ford E, Ayers S. Stressful events and support during birth: the effect on anxiety, mood and perceived control. J Anxiety Disord. 2009:23(2):260-8.

15. Conde A, Figueiredo B, Costa R, Pacheco A, Pais Á. Perception of the childbirth experience: continuity and changes over the postpartum period. J Reprod Infant Psychol. 2008;26(2):139-54.
16. Kordi M, Bakhshi M, Tara F. The effect of continuous childbirth support on the progress of labor in primipara women. JOGI. 2014;17(107):7-14.

17. Zafarmandi N, Hodavand S, Torkestani F, Zaeri F, Variji M. Prevalence of anxiety and fear of postpartum birth in women referred to selected hospitals. J Iran Med Counc. 2005;23(2):155-60.

18. Jafari E, Mohebbi P, Mazloomzadeh S. Factors related to women's childbirth satisfaction in physiologic and routine childbirth groups. Iran J Nurs Midwifery Res. 2017;22(3):219-24.

19. Fowler G, Patterson D. Use of maternity surveys in improving the care experience - a review of the evidence. Br J Midwifery. 2013;21(6):410-5.

20. Naseriasl M, Pourreza A, Akbari F, Rahimi A. The effect of socioeconomic factors on cesarean section rate in hospitals of Ardabil province in 2009. J Health. 2009:4(4):349-59.

21. Tocchioni V, Seghieri C, De Santis G, Nuti S. Socio-demographic determinants of women's satisfaction with prenatal and delivery care services in Italy. Int J Qual Health Care. 2018;30(8):594-601.

22. Omani-Samani $R$, Hollins Martin CJ, Martin CR. The birth satisfaction scalerevised Indicator (BSS-RI): a validation study in Iranian mothers. J Matern Fetal Neonatal Med. 2019;7:1-5.

23. Population and Housing Censuses: Detailed results of census 2016. https:// www.amar.org.ir/english/Population-and-Housing-Censuses/Census-2016Detailed-Results.

24. Demographic Yearbook 2018. https://www.sabteahval.ir/avej/Page. aspx?mld=49823\&lD=3199\&Page=Magazines/SquareshowMagazine.

25. Spielberger CD. Test anxiety inventory: "test attitude inventory". Palo Alto, Calif: Consulting Psychologists Press; 1980

26. Julian LJ. Measures of anxiety: State-Trait Anxiety Inventory (STAI), Beck Anxiety Inventory (BAI), and Hospital Anxiety and Depression Scale-Anxiety (HADS-A). Arthritis Care Res. 2011;63(Suppl 11(0 11)):S467-72.

27. American Cancer Societymedical and editorial content team. Dehydration and Lack of Fluids. 2020. https://www.cancer.org/treatment/treatments-andside-effects/physical-side-effects/fluids-and-dehydration.html.

28. Zhang J, Landy HJ, Branch DW, Burkman R, Haberman S, Gregory KD, Hatjis CG, Ramirez MM, Bailit JL, Gonzalez-Quintero VH, et al. Contemporary patterns of spontaneous labor with normal neonatal outcomes. Obstet Gynecol. 2010;116(6):1281-7.

29. Hollins Martin CJ, Martin CR. Development and psychometric properties of the birth satisfaction scale-revised (BSS-R). Midwifery. 2014:30(6):610-9.

30. Martin CR, Hollins Martin CJ, Burduli E, Barbosa-Leiker C, Donovan-Batson C. The birth satisfaction scale - revised (BSS-R): should the subscale scores or the total score be used? J Reprod Infant Psychol. 2018;36(5):530-5.

31. Martin CR, Hollins Martin CJ, Burduli E, Barbosa-Leiker C, Donovan-Batson C, Fleming SE. Measurement and structural invariance of the US version of the birth satisfaction scale-revised (BSS-R) in a large sample. Women Birth. 2017; 30(4):e172-8

32. Vardavaki Z, Hollins Martin CJ, Martin CR. Construct and content validity of the Greek version of the birth satisfaction scale (G-BSS). J Reprod Infant Psychol. 2015;33(5):488-503.

33. Goncu Serhatlioglu S, Karahan N, Hollins Martin CJ, Martin CR. Construct and content validity of the Turkish birth satisfaction scale - revised (T-BSS-R). J Reprod Infant Psychol. 2018;36(3):235-45.

34. Jefford E, Hollins Martin CJ, Martin CR. Development and validation of the Australian version of the birth satisfaction scale-revised (BSS-R). J Reprod Infant Psychol. 2018;36(1):42-58.

35. Nespoli A, Colciago E, Pedroni S, Perego S, Fumagalli S. The birth satisfaction scale-revised (BSS-R): process of translation and adaptation in an Italian context. Annali dell'Istituto superiore di sanita. 2018;54(4):340-7.

36. Romero-Gonzalez B, Peralta-Ramirez MI, Caparros-Gonzalez RA, CambilLedesma A, Hollins Martin CJ, Martin CR. Spanish validation and factor structure of the birth satisfaction scale-revised (BSS-R). Midwifery. 2019; 70:31-7.

37. Goodman P, Mackey MC, Tavakoli AS. Factors related to childbirth satisfaction. JNA. 2004:46(2):212-9.

38. Moudi Z, Tavousi M. Evaluation of Mackey childbirth satisfaction rating scale in Iran: what are the psychometric properties? Nurs Midwifery Stud. 2016; 5(2):e29952.

39. VanVoorhis CRW, Morgan BL. Understanding power and rules of thumb for determining sample sizes. Tutor Quant Methods Psychol. 2007;3(2):43-50.

40. Kline RB. Principles and practice of structural equation modeling. 3rd ed. London: Guilford Press; 2011. 
41. Taheri M, Takian A, Taghizadeh Z, Jafari N, Sarafraz N. Creating a positive perception of childbirth experience: systematic review and meta-analysis of prenatal and intrapartum interventions. BMC Anesthesiol. 2018;15(1):73.

42. Hodnett ED. Pain and women's satisfaction with the experience of childbirth: a systematic review. Am J Obstet Gynecol. 2002;186(5 Suppl Nature):S160-72

43. Frankman EA, Wang $\mathrm{L}$, Bunker $\mathrm{CH}$, Lowder JL. Episiotomy in the United States: has anything changed? Am J Obstet Gynecol. 2009;200(5):573.e1-7.

44. Vivilaki VG, Zemperligkou E, Iliopoulou E, Anastasopoulou E, Giaxi P, Lykeridou K. The reversed birth satisfaction scale: translation, adaptation and validation for a Greek sample. Eur J Midwifery. 2017;1(September):3.

45. Kartal B, Kızlırmak A, Calpbinici P, Demir G. Retrospective analysis of episiotomy prevalence. J Turk Ger Gynecol Assoc. 2017;18:190-4.

46. Belanger-Levesque MN, Pasquier M, Roy-Matton N, Blouin S, Pasquier JC. Maternal and paternal satisfaction in the delivery room: a cross-sectional comparative study. BMJ Open. 2014;4(2):e004013.

47. Sercekus $P$, Okumus $H$. Fears associated with childbirth among nulliparous women in Turkey. Midwifery. 2009;25(2):155-62.

48. Renfrew MJ, McFadden A, Bastos MH, Campbell J, Channon AA, Cheung NF, Silva DR, Downe S, Kennedy HP, Malata A, et al. Midwifery and quality care: findings from a new evidence-informed framework for maternal and newborn care. Lancet. 2014;384(9948):1129-45.

49. Sandall J, Soltani H, Gates S, Shennan A, Devane D. Midwife-led continuity models versus other models of care for childbearing women. Cochrane Database Syst Rev. 2016;4:CD004667.

50. Cheung W, Ip WY, Chan D. Maternal anxiety and feelings of control during labour: a study of Chinese first-time pregnant women. Midwifery. 2007;23(2): 123-30.

51. Fair CD, Morrison TE. The relationship between prenatal control, expectations, experienced control, and birth satisfaction among primiparous women. Midwifery. 2012;28(1):39-44.

52. Floris $\mathrm{L}$, Irion $\mathrm{O}$. Association between anxiety and pain in the latent phase of labour upon admission to the maternity hospital: a prospective, descriptive study. J Health Psychol. 2015;20(4):446-55.

53. Haines HM, Rubertsson C, Pallant JF, Hildingsson I. The influence of women's fear, attitudes and beliefs of childbirth on mode and experience of birth. BMC Pregnancy Childbirth. 2012;12:55

54. Fenaroli V, Molgora S, Dodaro S, Svelato A, Gesi L, Molidoro G, Saita E, Ragusa A. The childbirth experience: obstetric and psychological predictors in Italian primiparous women. BMC Pregnancy Childbirth. 2019;19(1):419.

55. Henriksen L, Grimsrud E, Schei B, Lukasse M. Factors related to a negative birth experience - a mixed methods study. Midwifery. 2017;51:33-9.

56. Bryanton J, Gagnon A, Johnston C, Hatem M. Predictors of women's perceptions of the childbirth experience. JOGNN. 2008;37:24-34.

57. Hodnett ED. Pain and women's satisfaction with the experience of childbirth: A systematic review. AJOG. 2002;186(5, Supplement):S160-72.

58. Waldenström U, Hildingsson I, Rubertsson C, Rådestad I. A negative birth experience: prevalence and risk factors in a national sample. Birth. 2004; 31(1):17-27.

59. Falk M, Nelson M, Blomberg M. The impact of obstetric interventions and complications on women's satisfaction with childbirth a population based cohort study including 16,000 women. BMC Pregnancy Childbirth. 2019; 19(1):494.

60. Nieminen K, Stephansson O, Ryding EL. Women's fear of childbirth and preference for cesarean section - a cross-sectional study at various stages of pregnancy in Sweden. Acta Obstet Gynecol Scand. 2009;88(7): 807-13.

61. Maharlouei N, Rezaianzadeh A, Hesami E, Moradi F, Mazloomi E, Joulaei H, Khodayari M, Lankarani KB. The preference of Iranian women to have normal vaginal or cesarean deliveries. J Res Med Sci. 2013;18(11):943-50.

62. Global Health Observatory Data Repository - World Health Organization. Births by caesarean section: Data by country. https://apps.who.int/gho/data/ node.main.BIRTHSBYCAESAREAN?lang=en.

63. Azami-Aghdash S, Ghojazadeh M, Dehdilani N, Mohammadi M, Asl Amin Abad R. Prevalence and causes of cesarean section in Iran: systematic review and meta-analysis. Iran J Public Health. 2014;43(5):545-55.

64. Sigurdardottir VL, Gamble J, Gudmundsdottir B, Kristjansdottir H, Sveinsdottir $H$, Gottfredsdottir $H$. The predictive role of support in the birth experience. Women Birth. 2017;30(6):450-9.
65. Hamm RF, Srinivas SK, Levine LD. 1032: can we identify risk factors for decreased birth satisfaction among women undergoing induction of labor? Am J Obstet Gynecol. 2019;220(1):S662-3.

66. Nerum H, Halvorsen L, Sorlie T, Oian P. Maternal request for cesarean section due to fear of birth: can it be changed through crisis-oriented counseling? Birth. 2006;33(3):221-8.

67. Smarandache A, Kim TH, Bohr Y, Tamim H. Predictors of a negative labour and birth experience based on a national survey of Canadian women. BMC Pregnancy Childbirth. 2016;16(1):114.

68. Neilson JP, Lavender T, Quenby S, Wray S. Obstructed labour. Br Med Bull. 2003;67(1):191-204

69. Jamilian M, Mobasseri S, Wakilian K, Jamilian HR. Effect of childbirth preparation classes on the duration of admission and satisfaction of mothers. J Ilam Univ Med Sci. 2012;21(2):44-50.

70. Crowe K, von Baeyer C. Predictors of a positive childbirth experience. Birth. 1989;16(2):59-63.

71. Yohai D, Alharar D, Cohen R, Kaltian Z, Aricha-Tamir B, Ben Aion S, Yohai Z, Weintraub AY. The effect of attending a prenatal childbirth preparedness course on labor duration and outcomes. J Perinat Med. 2018;46(1):47-52.

72. Howarth AM, Swain NR. Low-cost self-paced interventions increase birth satisfaction in first time fathers. Sex Reprod Healthc. 2020;24:100503.

73. Firoozbakht M, Nikpour M, Asadi S. The effect of birth preparation classes on labour. J Health Breeze. 2011;2(1):48-55.

74. Soriano-Vidal FJ, Vila-Candel R, Soriano-Martin PJ, Tejedor-Tornero A, CastroSanchez E. The effect of prenatal education classes on the birth expectations of Spanish women. Midwifery. 2018;60:41-7.

75. Al Ahmar E, Tarraf S. Assessment of the socio-demographic factors associated with the satisfaction related to the childbirth experience. Open J Obstet Gynecol. 2014;4(10):27.

\section{Publisher's Note}

Springer Nature remains neutral with regard to jurisdictional claims in published maps and institutional affiliations.
Ready to submit your research? Choose BMC and benefit from:

- fast, convenient online submission

- thorough peer review by experienced researchers in your field

- rapid publication on acceptance

- support for research data, including large and complex data types

- gold Open Access which fosters wider collaboration and increased citations

- maximum visibility for your research: over $100 \mathrm{M}$ website views per year

At BMC, research is always in progress.

Learn more biomedcentral.com/submissions 